\title{
PERFIL DOS FRUTICULTORES E DIAGNÓSTICO DO USO DE AGROTÓXICOS NO POLO DE FRUTICULTURA DE LIVRAMENTO DE NOSSA SENHORA, BAHIA
}

\author{
Suzany Aguiar Leite ${ }^{1}$ \\ Maria Aparecida Castellani ${ }^{2}$ \\ Ana Elizabete Lopes Ribeiro ${ }^{3}$ \\ Aldenise Alves Moreira ${ }^{4}$ \\ Weber Marcilio Malheiro Aguiar
}

\section{RESUMO}

O Brasil é o terceiro produtor mundial de frutas, destacando-se a Região Nordeste como uma das principais produtoras. Na Bahia, dez polos de fruticultura são importantes na exportação de frutas frescas. O polo de Livramento de Nossa Senhora tem referência nos cultivos da manga, maracujá e banana. O objetivo do trabalho foi realizar um diagnóstico sobre aspectos da produção de banana, manga e maracujá, voltados ao perfil do produtor, da propriedade e do uso de agrotóxicos, devolução de embalagens vazias e descarte de resíduos. Foram aplicados 610 questionários, abrangendo $20 \%$ dos produtores de cada frutífera. Os produtores têm baixo grau de escolaridade, dificultando a compreensão do uso de agrotóxicos de forma correta. A assistência técnica por meio de órgãos públicos é insuficiente e realizada pelos profissionais das casas comerciais. O uso de EPI não é prática persistente e a lavagem dos equipamentos é realizada em tanque de uso doméstico. Ações de educação sanitária devem ser desenvolvidas, com atenção aos produtores de maracujá, que, por serem mais jovens, podem se tornar multiplicadores dos conhecimentos necessários para uso de agrotóxicos.

Palavras-chave: banana, destino de embalagens, manga, maracujá, perfil do produtor.

\footnotetext{
${ }^{1}$ Graduada em Engenharia Agronômica (UESB). Mestre em Agronomia (UESB). Doutoranda em Agronomia (UESB). E-mail: suzanyleite@yahoo.com.br

${ }^{2}$ Graduada em Agronomia (UNESP). Mestre em Agronomia (UNESP). Doutora em Agronomia (UNESP). PósDoutora em Proteção de Plantas (UNESP). Professor Pleno, DFZ/UESB. E-mail: castellani@uesb.edu.br

${ }^{3}$ Graduada em Agronomia (UESB). Mestre em Agronomia (UESB). Doutora em Entomologia Agrícola (UFRPE). Pós-Doutora em Agronomia (UESB). Professor Adjunto do Núcleo Docente Multidisciplinar (UFOB). E-mail: ana.lopes@ufob.edu.br

${ }^{4}$ Graduada em Agronomia (UFAL). Mestre em Agronomia (UNESP). Doutora em Agronomia (UNESP). Pós Doutora em Proteção de Plantas (UNESP). Professor Pleno, DFZ/UESB. E-mail: aldenise.moreira@gmail.com

${ }^{5}$ Graduado em Engenharia Agronômica (UESB). Especialista em Defesa Sanitária Vegetal (UNIME). Mestre em Defesa Agropecuária (UFRB). Fiscal Estadual Agropecuário (ADAB). E-mail: weberaguiar@yahoo.com.br
} 


\title{
PROFILE OF FRUIT GROWERS AND DIAGNOSTIC USE OF PESTICIDES IN FRUIT THE PLACES LIVRAMENTO DE NOSSA SENHORA, BAHIA.
}

\begin{abstract}
Brazil is the third worldwide producer of fruit, highlighting the Northeast as one of the main producers. In Bahia ten places of fruit growing are important in the export of fresh fruit. The place Livramento de Nossa Senhora It has reference in crops of mango, passion fruit and banana. The aim of the study was accomplish an diagnosis of aspects of production banana, mango and passion fruit, associated to profile producing, the property and the use of pesticides, return of package empty and discard of residues. They were applied 610 questionnaires, to include $20 \%$ of the producers of each fruit. Producers have low literacy difficult to understand the use of pesticides correctly. Technical assistance by public bodies is insufficient and performed by professionals from business houses. The use of PPE is not persistent practice and washing equipment is carried on household tank. Shares of health education should be developed, with attention to producers of passionfruit, as they are younger, can become multipliers of knowledge necessary to use pesticides.
\end{abstract}

Keywords: banana, destination of package, mango, passion fruit, profile producing.

\section{INTRODUÇÃO}

O Brasil é o terceiro maior produtor mundial de frutas, destacando-se as regiões Sudeste, Nordeste e Sul como principais produtoras. Em 2010, O Estado de São Paulo respondeu por $32,9 \%$ da produção, seguido pela Bahia $(15,1 \%)$, Rio Grande do Sul (7,9\%), Minas Gerais (7,1\%), Pernambuco $(5,2 \%)$ e demais estados $(31,9 \%)$. É uma atividade econômica de destaque nos cenários econômico e social, pois envolve mais de 5 milhões de pessoas, sendo praticada, em média, em propriedades de até 10 ha, garantindo boa qualidade de vida às famílias produtoras (KIST et al., 2012).

$\mathrm{Na}$ Bahia, a fruticultura ocupa posição de destaque no agronegócio e está presente em todas as regiões do estado, totalizando dez polos consolidados e estruturados também para exportação de frutas frescas. No Sudoeste da Bahia,a agricultura irrigada da Bacia do Rio de Contas, que envolve o polo de fruticultura de Livramento de Nossa Senhora, tem como referência o cultivo da manga, maracujá e banana, com perspectivas de diversificação da produção, incluindo plantios como goiaba e abacaxi (SEAGRI, 2013).

Os cultivos frutícolas apresentam diversos problemas fitossanitários, decorrentes do ataque de pragas, doenças e plantas daninhas, levando, muitas vezes, o produtor a adotar medidas de controle nos pomares. O controle químico, por meio da utilização de agrotóxicos, geralmente, destaca-se como método mais utilizado, porém, nem sempre de forma racional.

O uso da tática do controle químico deve ser fundamentado nos conhecimentos que envolvem desde o monitoramento das pragas e doenças, tomada de decisão pela aplicação ou não, seleção do produto, tecnologia de aplicação, medidas de segurança e proteção individual até o destino final das embalagens e dos resíduos, dentre outros aspectos, para minimizar riscos de contaminação do meio ambiente, intoxicação do aplicador e resíduos nos alimentos. 
Alguns estudos desenvolvidos na Bahia têm indicado que os produtores de pinha possuem baixa escolaridade (OLIVEIRA, 2012); inexpressiva participação em cooperativas e associações de classe, tanto dos produtores de pinha como de graviola (FREITAS et al., 2013; OLIVEIRA, 2012); pouco ou nenhum conhecimento sobre a Lei dos Agrotóxicos pelos produtores de manga (BRANDÃO, 2009), pinha (OLIVEIRA, 2012) e graviola (FREITAS et al., 2013); e necessidade de investimentos em assistência técnica especializada (FREITAS et al., 2013; OLIVEIRA, 2012). No entanto, os dados são pontuais sobre determinada cultura, não existindo informações sobre os polos de fruticultura da Bahia e seus principais cultivos. Assim, o objetivo do trabalho foi realizar um diagnóstico sobre aspectos da produção de banana, manga e maracujá, voltados para o perfil do produtor, da propriedade e do uso de agrotóxicos, devolução de suas embalagens vazias e descarte de resíduos, com o intuito de subsidiar o planejamento de ações de educação sanitária aos fruticultores do polo de fruticultura de Livramento de Nossa Senhora, BA.

\section{MATERIAL E MÉTODOS}

O estudo foi realizado no polo de Fruticultura de Livramento de Nossa Senhora, BA, no perímetro irrigado e suas adjacências, que abrange propriedades dos municípios de Livramento de Nossa Senhora e Dom Basílio, localizados no polígono das Secas, no semiárido baiano, com aproximadamente 12 mil ha. Livramento de Nossa Senhora, município que concentra a maioria das propriedades, dista aproximadamente $722 \mathrm{~km}$ de Salvador e compreende uma superfície de 2.291 $\mathrm{km}^{2}$, situando-se nas coordenadas $13^{\circ} 15^{\prime}$ de latitude sul e 41050' de longitude oeste, a uma altitude média de $480 \mathrm{~m}$, com precipitação média de $760 \mathrm{~mm}$ anuais e temperatura média anual de $22,6^{\circ} \mathrm{C}$. O estudo foi desenvolvido nos meses de novembro e dezembro de 2010. O tamanho da amostra foi definido a partir dos dados cadastrais existentes na Agência Estadual de Defesa Agropecuária do Estado da Bahia (ADAB), unidade de Livramento de Nossa Senhora. O tamanho da amostra foi estimado utilizando-se a fórmula de Thompson (1992) apud Zart et al. (2011), que leva em conta o tamanho da população alvo, o erro admitido e o desvio padrão de uma variável que caracterize essa população, bem como o valor tabelado do grau de confiança estabelecido (95\%). Utilizou-se a seguinte fórmula para estimar o tamanho da amostra:

$$
n=\frac{1}{\left(\frac{r^{2}}{z^{2} \cdot y^{2}}+\frac{1}{N}\right)}
$$

Em que: $\mathrm{n}=$ Tamanho amostral; $r=$ margem de erro de uma variável significativa da população; $z$ = grau de confiança (95\%); y = desvio padrão de uma variável significativa da população e $\mathrm{N}=$ número total de indivíduos da população considerada.

Aplicando-se a fórmula, estimou-se o tamanho mínimo da amostra, abrangendo $20 \%$ da população de produtores de manga, maracujá e banana, totalizando 330, 240 e 40 produtores, respectivamente (Tabela 1). 
Tabela 1- População total, população amostrada, grau de confiança, desvio padrão e erro amostral

\begin{tabular}{lccccc}
\hline Cultura & $\begin{array}{c}\text { População } \\
\text { total }\end{array}$ & $\begin{array}{c}\text { População } \\
\text { amostrada }\end{array}$ & $\begin{array}{c}\text { Grau de } \\
\text { confiança (\%) }\end{array}$ & $\begin{array}{c}\text { Desvio } \\
\text { padrão }\end{array}$ & $\begin{array}{c}\text { Erro amostral } \\
(\%)\end{array}$ \\
\hline Manga & 1650 & 330 & 95 & 0,65 & 3,0 \\
Maracujá & 1200 & 240 & 95 & 0,65 & 3,5 \\
Banana & 200 & 40 & 95 & 0,65 & 8,5 \\
Total & 3050 & 610 & & & \\
\hline
\end{tabular}

Fonte: dados da pesquisa

As propriedades foram selecionadas por amostragem aleatória, a partir dos dados cadastrais existentes na ADAB, unidade de Livramento de Nossa Senhora. O questionário foi elaborado com 36 perguntas, estruturadas de múltipla escolha, resposta livre, por faixa e dicotômica, englobando os seguintes aspectos: 1) Perfil do fruticultor: idade, grau de escolaridade, local de residência, tipo de posse da terra e participação em segmentos organizados da sociedade; 2) Perfil da propriedade: área total, área cultivada com manga, maracujá e banana, idade do pomar e mão de obra utilizada; 3) Problemas fitossanitários: pragas e doenças mais comuns e métodos de controle de pragas, doenças e plantas daninhas utilizados; 4) Uso de agrotóxicos: responsável pela aplicação, frequência da aplicação, idade do aplicador, orientação técnica, período de carência, tipo e manutenção do equipamento e receituário agronômico; 5) Uso seguro e destino das embalagens e resíduos: uso de Equipamento de Proteção Individual (EPI), local de lavagem do EPI, tríplice lavagem, perfuração do fundo das embalagens utilizadas, destino final das embalagens e destino dos resíduos de pulverizadores. A aplicação dos questionários consistiu de visitas às propriedades selecionadas, realizando as entrevistas com os fruticultores de cada cultura.

As questões de respostas livres foram enquadradas em categorias estabelecidas pelos autores: como idade do produtor e idade do aplicador, quantificadas nas faixas de: $18-30 ; 31-40 ; 41-50$ e acima de 50 ; e área cultivada: 1 5; 5,1-10; 10,1-15; acima de 15 hectares, idade dos pomares: 1-5; 5,1-10; 10,1-15; 15,1-20; 20,1-25 e acima de 25 anos. Os dados obtidos foram tabulados, calculando-se as porcentagens das respostas de cada quesito em relação ao total de produtores entrevistados de cada frutífera e ao total geral de produtores, com análise descritiva dos mesmos.

\section{RESULTADOS E DISCUSSÃO}

A maioria dos fruticultores (65\%) do polo de Livramento de Nossa Senhora possui idade acima dos 41 anos, ocorrendo variação na faixa etária em função do tipo de fruteira cultivada. No cultivo de banana, predominam produtores com mais de 50 anos (75\%), em manga a faixa etária concentra-se em idades acima de 41 anos (30\% de 41 a 50 anos e $49 \%$ acima de 50 anos), sendo mais jovens os produtores de maracujá, pois $55 \%$ dos mesmos possuem até 40 anos (Tabela 2). 
Tabela 2 - Síntese (\%) das respostas sobre perfil do produtor de banana, manga e maracujá do polo de fruticultura de Livramento de Nossa Senhora, Bahia.

\begin{tabular}{|c|c|c|c|c|}
\hline Questões do diagnóstico & $\begin{array}{c}\text { Banana } \\
(\%)\end{array}$ & $\begin{array}{c}\text { Manga } \\
(\%)\end{array}$ & $\begin{array}{c}\text { Maracujá } \\
(\%)\end{array}$ & Total (\%) \\
\hline \multicolumn{5}{|l|}{ Idade do Produtor: } \\
\hline $18-30$ & 2 & 5 & 30 & 14,7 \\
\hline $31-40$ & 11 & 16 & 25 & 20,3 \\
\hline $41-50$ & 12 & 30 & 25 & 28,4 \\
\hline Acima de 50 & 75 & 49 & 20 & 36,6 \\
\hline \multicolumn{5}{|l|}{ Grau de escolaridade } \\
\hline Analfabeto & 2 & 1 & 1 & 1,3 \\
\hline Assina o nome & 5 & 6 & 3 & 4,7 \\
\hline $\begin{array}{l}\text { Ensino fundamental } \\
\text { incompleto }\end{array}$ & 70 & 39 & 60 & 49,6 \\
\hline $\begin{array}{l}\text { Ensino fundamental } \\
\text { completo }\end{array}$ & 3 & 14 & 11 & 12 \\
\hline Ensino médio incompleto & 5 & 7 & 10 & 7,8 \\
\hline Ensino médio completo & 15 & 27 & 13 & 20,6 \\
\hline Superior incompleto & - & - & 1 & 0,5 \\
\hline Superior completo & - & 6 & 1 & 3,5 \\
\hline \multicolumn{5}{|l|}{ Tipo da posse da terra: } \\
\hline $\begin{array}{l}\text { Proprietário } \\
\text { Plat }\end{array}$ & 83 & 94 & 56 & 77,6 \\
\hline Ocupante & - & - & 1 & 0,3 \\
\hline Parceiro & 7 & 2 & 5 & 3,4 \\
\hline Arrendatário & 5 & 2 & 5 & 3,7 \\
\hline Assentado & 5 & - & - & 0,3 \\
\hline Meeiro & - & 1 & 33 & 14,2 \\
\hline Comodato & - & 1 & - & 0,5 \\
\hline \multicolumn{5}{|l|}{$\begin{array}{l}\text { Participação em } \\
\text { organizações de classe: }\end{array}$} \\
\hline Cooperativa & 33 & 37 & 17 & 29,5 \\
\hline Associacão & 42 & 33 & 45 & 37,9 \\
\hline Sindicato rural & 20 & 12 & 16 & 14,1 \\
\hline Clube recreativo & 2 & 7 & - & 4,4 \\
\hline Partido político & 3 & 5 & 1 & 3,1 \\
\hline Associação cultural & - & 1 & - & 0,3 \\
\hline Nenhuma & - & 5 & 21 & 10,7 \\
\hline Outra & - & - & - & - \\
\hline
\end{tabular}

Esses dados concordam com aqueles apresentados para produtores de guaraná de Alta Floresta, MT, onde a maioria dos produtores $(84,4 \%)$ possui idade superior a 41 anos (GOUVEIA et al., 2012), fato não constatado por Matias et al. (2003) para fruticultores de Limoeiro do Norte, CE, onde 31,3\% tem idade de 41-50 anos e apenas 6,2\% têm idade superior a 50 anos, demostrando que parte dos produtores são mais jovens, situação constatada para os produtores de maracujá da região em estudo. De modo geral, a escolaridade dos produtores é baixa. Quase metade da população entrevistada $(49,6 \%)$ possui o ensino fundamental incompleto, seguido de ensino médio completo $(20,6 \%)$ e fundamental completo (12\%), com pequena variação entre produtores das três fruteiras, destacando-se os produtores de manga com maior escolaridade, pois $27 \%$ possuem o ensino médio completo, havendo, ainda, produtores analfabetos (6\%), sendo nesta condição englobados, também, aqueles que só assinam o nome (Tabela 2). O baixo grau de escolaridade é um dos fatores que contribuem para o risco de intoxicação por agrotóxicos, devido 
à dificuldade na compreensão das informações contidas nos rótulos (BEDOR et al., 2009; PERES; MOREIRA, 2007; et al.,). Ainda, segundo Zarth et al. (2011), em trabalho com produtores de uva, o baixo grau de escolaridade dos produtores associado à idade acima de 50 anos são fatores que dificultam a realização de mudanças nos controles e processos da atividade, além da tendência, em algumas propriedades, de abandono da atividade por falta de mão-de-obra pelo êxodo do jovem do meio rural.

A maioria dos produtores é proprietário da terra, atingindo $77,6 \%$ no total e $83 \%, 94 \%$ e $56 \%$ para os cultivos de banana, manga e maracujá, respectivamente. Dos produtores de maracujá, um percentual expressivo (33\%) trabalha na condição de meeiro. Outros tipos de posse da terra foram menos expressivos, como ocupante $(0,3 \%)$, parceiro $(3,4 \%)$, arrendatário $(3,7 \%)$, assentado $(0,3 \%)$ e comodato $(0,5 \%)$ (Tabela 2). A maioria $(79,1 \%)$ dos produtores não reside nas propriedades, variando de $77 \%$ a $90 \%$ para produtores de maracujá e banana, respectivamente. Quanto aos aspectos relacionados à posse da terra em Boa Vista, RR, 81,34\% dos horticultores entrevistados são proprietários da terra (LIMA et al., 2011). De modo geral, $81,5 \%$ dos produtores participam de organizações de classe, como cooperativa $(29,5 \%)$, associação $(37,9 \%)$ e sindicato rural $(14,1 \%)$, principalmente (Tabela 2$)$. Este fato é interessante, uma vez que a organização em associações é de grande importância, no sentido de adoção de novas tecnologias e uso de tecnologias limpas, pois o mercado exterior é cada vez mais exigente (SILVA; FRANCISCO; BAPTISTELLA, 2008). Acredita-se que o fortalecimento da cooperativa local própria, gerenciada por fruticultores, e a ampliação da participação dos fruticultores serviriam de suporte técnico, de fomento à produção e apoio aos processos de comercialização, conforme constatado para a produção de batata (REICHERT et al., 2011).

No polo de fruticultura de Livramento de Nossa Senhora, a banana é cultivada em áreas de até 10 ha no máximo, sendo que $95 \%$ das propriedades não ultrapassam 5 ha. A manga é cultivada principalmente em áreas de até 5 ha (72\%), havendo no entanto, uma distribuição em todos os tamanhos estudados, sendo que $2 \%$ das propriedades ultrapassam 25 ha. Seguindo o mesmo padrão, os cultivos de maracujá predominam em áreas de até 5 ha (93\%), com pequena porcentagem de cultivos entre 5 e 15 ha (6\%) (Tabela 3).

Os pomares de banana são novos, sendo a maioria (95\%) na faixa de 1 a 5 anos; já os pomares de manga são mais antigos, concentrando-se (82\%) na faixa entre 5 a 15 anos de idade, com 13\% com mais de 15 anos. A manga é a frutífera que predomina na região, sendo o seu cultivo mais antigo e tradicional no polo de Livramento. Quanto ao maracujá, pela própria característica da cultura, todos os pomares apresentaram idade na faixa de 1 a 5 anos (Tabela 3), o que era esperado, pois a vida útil de um pomar dessa cultura na região não ultrapassa 11 a 12 meses, em função de problemas fitossanitários, como a fusariose e diversas viroses, tornando-se praticamente obrigatória a erradicação das plantas após esse período. A mão de obra utilizada nas propriedades é predominantemente familiar nos cultivos de banana ( $86 \%$ ) e maracujá $(55 \%)$, sendo que, em manga, a mão de obra familiar $(32 \%)$ e diaristas (36\%) compreendem a maioria, destacando-se também maior percentual de empregados fixos (10\%) em relação às outras fruteiras (Tabela 3). 
Tabela 3 - Síntese das respostas sobre perfil da propriedade cultivadas com banana, manga e maracujá. Livramento de Nossa Senhora, Bahia

\begin{tabular}{|c|c|c|c|c|}
\hline $\begin{array}{l}\text { Questões do } \\
\text { diagnóstico }\end{array}$ & $\begin{array}{c}\text { Banana } \\
(\%)\end{array}$ & $\begin{array}{c}\text { Manga } \\
(\%)\end{array}$ & $\begin{array}{c}\text { Maracujá } \\
(\%)\end{array}$ & Total (\%) \\
\hline \multicolumn{5}{|l|}{ Área cultivada: } \\
\hline $1-5$ & 95 & 72 & 93 & 81,9 \\
\hline $5,1-10$ & 5 & 19 & 5 & 13,1 \\
\hline $10,1-15$ & - & 3 & 1 & 2,1 \\
\hline $15,1-20$ & - & 3 & - & 1,5 \\
\hline $20,1-25$ & - & 1 & - & 0,3 \\
\hline Acima de 25 & - & 2 & 1 & 1,2 \\
\hline \multicolumn{5}{|l|}{ Idade do pomar: } \\
\hline $1-5$ & 95 & 5 & 100 & 44,9 \\
\hline $5,1-10$ & 5 & 45 & - & 26,1 \\
\hline $10,1-15$ & - & 37 & - & 21,4 \\
\hline Acima de 15 & - & 13 & - & 7,6 \\
\hline \multicolumn{5}{|l|}{$\begin{array}{l}\text { Mão de obra utilizada na } \\
\text { propriedade: }\end{array}$} \\
\hline Familiar & 86 & 32 & 55 & 42,7 \\
\hline $\begin{array}{l}\text { Empregados fixos todos } \\
\text { com carteira assinada }\end{array}$ & 4 & 10 & - & 6,4 \\
\hline $\begin{array}{l}\text { Empregados: parte fixo } \\
\text { com carteira assinada e } \\
\text { parte sem carteira }\end{array}$ & - & 2 & 1 & 1,5 \\
\hline Temporários & 5 & 15 & 3 & 10 \\
\hline $\begin{array}{l}\text { Empregados sem carteira } \\
\text { assinada }\end{array}$ & - & 3 & - & 1,8 \\
\hline Meeiros/parceiros & - & 2 & 20 & 8,1 \\
\hline Diaristas & 5 & 36 & 21 & 29,5 \\
\hline
\end{tabular}

Fonte: dados da pesquisa

As respostas sobre os problemas fitossanitários indicaram que os tripes são pragas importantes para as três frutíferas. A cultura com maiores indicações de problemas fitossanitários, tanto pragas como doenças, foi a manga; no entanto, as moscas-das-frutas, pragas quarentenárias, quando se visa exportação para os mercados americano e japonês, foram indicadas apenas por $5 \%$ dos produtores de manga, assumindo maior frequência nas respostas tripes (32\%), lagarta (40\%) e gafanhoto (13\%). Em banana, constata-se reduzido número de problemas fitossanitários, segundo os produtores, destacando-se, nas respostas, tripes (33\%), ácaro (34\%) e "mosquito" (33\%), sendo este não identificado. Quanto ao maracujá, as respostas foram bastante coerentes com os problemas fitossanitários comuns na cultura, como tripes (30\%), lagarta $(34 \%)$, ácaro $(4 \%)$, percevejo $(3 \%)$ e mosca branca (21\%) (Tabela 4). 
Tabela 4 - Síntese das respostas sobre problemas fitossanitários nos cultivos de banana, manga e maracujá. Livramento de Nossa Senhora, Bahia

\begin{tabular}{|c|c|c|c|c|}
\hline $\begin{array}{l}\text { Questões do } \\
\text { diagnóstico } \\
\text { Pragas comuns nos } \\
\text { pomares: }\end{array}$ & $\begin{array}{c}\text { Banana } \\
(\%)\end{array}$ & $\begin{array}{c}\text { Manga } \\
(\%)\end{array}$ & $\begin{array}{c}\text { Maracujá } \\
(\%)\end{array}$ & Total (\%) \\
\hline Tripes & 33 & 32 & 30 & 31,5 \\
\hline Lagarta & - & 40 & 34 & 37,7 \\
\hline Gafanhoto & - & 13 & - & 8,2 \\
\hline Cochonilha & - & 5 & - & 3,4 \\
\hline Pulgão & - & 2 & - & 1,3 \\
\hline Ácaro & 34 & - & 4 & 1,6 \\
\hline Moscas-das-frutas & - & 5 & - & 3,2 \\
\hline Vaquinha & - & 1 & - & 0,8 \\
\hline Percevejo & - & 1 & 3 & 1,3 \\
\hline Mosca branca & - & 1 & 21 & 7,9 \\
\hline Mosquito & 33 & - & - & 0,2 \\
\hline Outros & - & - & 8 & 2,9 \\
\hline \multicolumn{5}{|l|}{$\begin{array}{l}\text { Doenças comuns } \\
\text { nos pomares: }\end{array}$} \\
\hline Antracnose & - & 84 & 18 & 62,5 \\
\hline Oídio & - & 2 & - & 1,4 \\
\hline Virose & - & - & 77 & 23,6 \\
\hline Fusariose & - & - & 2 & 1,4 \\
\hline Outros & - & 14 & 3 & 11,1 \\
\hline \multicolumn{5}{|l|}{$\begin{array}{l}\text { Métodos de controle } \\
\text { das pragas: }\end{array}$} \\
\hline Nenhum controle & 62 & - & - & 4,4 \\
\hline Controle cultural & - & - & - & - \\
\hline Controle biológico & - & 1 & - & 0,5 \\
\hline Controle genético & - & - & & \\
\hline Controle químico & 38 & 99 & 100 & 95,1 \\
\hline \multicolumn{5}{|l|}{$\begin{array}{l}\text { Métodos de controle } \\
\text { de plantas daninhas: }\end{array}$} \\
\hline Capina & 41 & 23 & 64 & 38,3 \\
\hline Roçagem & 38 & 45 & 16 & 34,8 \\
\hline Herbicida & 21 & 32 & 19 & 26,6 \\
\hline Outro método & - & - & 1 & 0,3 \\
\hline
\end{tabular}

Fonte: dados da pesquisa

No entanto, é importante considerar que, como não foram mostradas fotografias ou outros tipos de ilustrações para identificação ou confirmação dos problemas fitossanitários citados, acredita-se que as respostas tenham sido, de certa forma, imprecisas, a exemplo do problema "mosquito" mencionado por $33 \%$ dos produtores de banana, sobre o qual não se encontra informações relacionadas na literatura. Não foram citadas a ocorrência de doenças em bananeiras, destacando-se antracnose (84\%) e virose (77\%) nas respostas dos produtores de manga e maracujá, respectivamente.

Quanto aos métodos de controle de pragas, houve predomínio do controle químico em manga (99\%) e maracujá (100\%), e ausência de controle $(62 \%)$ em banana. Além do químico, o controle biológico foi o único citado. Todos os produtores realizam controle de plantas daninhas, com distribuição relativamente uniforme entre capina, roçagem e herbicida, exceto para maracujá, cujo controle que se destacou foi a capina (64\%). Outras técnicas de controle de pragas alternativas 
aos agrotóxicos são, hoje, uma realidade, tanto em termos da produtividade quanto em relação aos custos, além de apresentarem um potencial de contaminação humana ou ambiental muito menor (PERES; MOREIRA, 2007). No entanto, os produtores entrevistados aparentam não ter conhecimento sobre os outros métodos de controle. De modo geral, o controle químico é empregado nos três cultivos, tanto para controlar pragas e doenças, como para controle das plantas daninhas. A responsabilidade das aplicações é do próprio fruticultor, na maioria dos cultivos de banana $(78 \%)$ e maracujá $(91 \%)$, enquanto que em manga esse serviço é terceirizado na maioria dos casos (73\%) (Tabela 5$)$.

De modo geral, a grande maioria dos aplicadores (84,9\%) apresenta idade entre 18 e 50 anos, com destaque para o maracujá, com 47\% na faixa etária de 18 a 30 anos (Tabela 5). Grande percentual de produtores $(47,2 \%)$ não recebe orientação técnica, atingindo $87 \%$ em banana e $59 \%$ em maracujá, sendo os produtores de manga melhor assistidos. No entanto, essa orientação técnica, quando ocorre, é proveniente das casas comerciais, principalmente de revenda dos agrotóxicos (61,4\% no total) e com inexpressiva a participação de órgãos públicos $(0,8 \%)$. Isso reflete no grande percentual de produtores que não usam receituário agronômico $(51,9 \%)$, destacando-se os cultivos de banana (77\%) e maracujá $(62 \%)$ (Tabela 5$)$. Essa realidade já havia sido constatada para produtores de manga do polo de fruticultura de Livramento de Nossa Senhora por Brandão (2009). A autora verificou que a maioria dos produtores de pomares monitorados para controle de moscasdas-frutas recebe assistência através do responsável técnico, e que, em pomares não monitorados, a maioria dos entrevistados tem assistência através das casas comerciais. No entanto, a autora ressalta que a orientação dos fruticultores deveria ser realizada por órgãos públicos e responsáveis técnicos, já que os vendedores das lojas não estão devidamente preparados para orientar os agricultores, como se relata em trabalho de Bedor et al. (2007). A falta de assistência técnica especializada parece ser um grande entrave para o desenvolvimento e inovação da horticultura como um todo. Na Região de Araras, SP, $28 \%$ das propriedades, principalmente as de cultivos de hortaliças e frutas, não contam com orientação de engenheiros agrônomos (MONQUERO; INÁNCIO; SILVA, 2009). Na fruticultura irrigada do polo fruticultor do submédio do Vale de São Francisco, a assistência técnica relacionada com o manejo de agrotóxicos no local de trabalho é precária. Essa falta de acompanhamento técnico revela que os tomadores de decisão levam em conta somente a produtividade e o rendimento financeiro (BEDOR, 2009). 
Tabela 5 - Síntese das respostas sobre uso de agrotóxicos nos cultivos de banana, manga e maracujá. Livramento de Nossa Senhora, Bahia

\begin{tabular}{|c|c|c|c|c|}
\hline $\begin{array}{l}\text { Questões do } \\
\text { diagnóstico }\end{array}$ & Banana (\%) & Manga (\%) & Maracujá (\%) & Total (\%) \\
\hline \multicolumn{5}{|l|}{$\begin{array}{l}\text { Responsável pela } \\
\text { aplicação: }\end{array}$} \\
\hline Fruticultor & 78 & 27 & 91 & 56,8 \\
\hline Terceirizado & 22 & 73 & 9 & 43,2 \\
\hline \multicolumn{5}{|l|}{$\begin{array}{l}\text { Frequência de } \\
\text { aplicação: }\end{array}$} \\
\hline Aplica sempre & 5 & 59 & 90 & 66,7 \\
\hline Não aplica & 37 & 1 & 1 & 2,9 \\
\hline Às vezes & 58 & 21 & 9 & 19,3 \\
\hline Trator da associação & - & 19 & - & 11,1 \\
\hline \multicolumn{5}{|l|}{ Idade do aplicador: } \\
\hline $18-30$ & 20 & 9 & 47 & 21,6 \\
\hline $31-40$ & 33 & 26 & 26 & 26,2 \\
\hline $41-50$ & 33 & 46 & 19 & 37,1 \\
\hline Acima de 50 & 14 & 19 & 08 & 15,1 \\
\hline \multicolumn{5}{|l|}{ Orientação técnica: } \\
\hline Sim & 13 & 67 & 41 & 52,8 \\
\hline Não & 87 & 33 & 59 & 47,2 \\
\hline \multicolumn{5}{|l|}{$\begin{array}{l}\text { Orientação técnica } \\
\text { através de: }\end{array}$} \\
\hline Casa comercial & 45 & 47 & 84 & 61,4 \\
\hline Órgão público & 2 & - & 1 & 0,8 \\
\hline Responsável técnico & 8 & 37 & 4 & 21,6 \\
\hline Outro & 49 & 16 & 11 & 16,2 \\
\hline \multicolumn{5}{|l|}{ Receita agronômica } \\
\hline Usa & 23 & 59 & 38 & 48,1 \\
\hline Não usa & 77 & 41 & 62 & 51,9 \\
\hline
\end{tabular}

Fonte: dados da pesquisa

A capacitação profissional dos vendedores de lojas de produtos agrícolas e o rigor na fiscalização dos órgãos responsáveis pelo uso de agrotóxicos junto aos produtores rurais são atividades importantes nesse contexto (BEDOR, 2008). A carência de políticas governamentais voltadas ao acompanhamento e fiscalização das atividades do homem do campo afasta ainda mais os agricultores dos saberes disponíveis sobre as práticas de proteção de lavouras e combate às pragas. Somam-se a esses fatores a forte influência das políticas de incentivo à produção agrícola, quase todas fortemente associadas ao aumento do consumo de agentes químicos, em particular agrotóxicos (PERES; MOREIRA, 2007). A partir de 1990, as entidades públicas de extensão rural do Brasil, que sobreviveram ao desmonte e privatização, fizeram um esforço para se readequarem aos novos tempos, sem a obtenção dos resultados desejados, pois ficavam presos às estruturas institucionais e a metodologias parcialmente participativas (KREUTZ; PINHEIROS; CAZELLA, 2005). Na Bahia, a Empresa Baiana de Desenvolvimento Agrícola, EBDA, responsável pelas ações de acesso a serviços de extensão rural gratuitos, foi extinta em 2015, agravando ainda mais a situação de precariedade dos serviços.

O uso do EPI completo é praticado por $38 \%$ dos produtores, sendo que boa parte $(41 \%)$ usa luva, bota, macacão e máscara. Um dado preocupante é que a maioria dos produtores $(52,6 \%)$ lava o EPI em tanques de uso doméstico, destacando-se o maracujá, com $81 \%$ dos produtores que realizam tal prática (Tabela $6)$. 
Tabela 6 - Síntese das respostas sobre o uso de Equipamento de proteção individual (EPI), destino final das embalagens e dos resíduos de agrotóxicos nos cultivos de banana, manga e maracujá. Livramento de Nossa Senhora, Bahia

\begin{tabular}{|c|c|c|c|c|}
\hline $\begin{array}{l}\text { Questões do } \\
\text { diagnóstico }\end{array}$ & Banana (\%) & Manga (\%) & Maracujá (\%) & Total (\%) \\
\hline \multicolumn{5}{|l|}{ EPI } \\
\hline Usa completo & 29 & 58 & 23 & 38,2 \\
\hline Não usa EPI & 7 & 6 & 16 & 10,8 \\
\hline $\begin{array}{l}\text { Luva, bota, macacão e } \\
\text { máscara }\end{array}$ & 62 & 31 & 60 & 41,5 \\
\hline Outro & 2 & 5 & 1 & 9,5 \\
\hline \multicolumn{5}{|l|}{ Onde lava o EPI } \\
\hline $\begin{array}{l}\text { Tanque de uso } \\
\text { doméstico }\end{array}$ & 35 & 34 & 81 & 52,6 \\
\hline Local apropriado & 65 & 66 & 19 & 47,4 \\
\hline \multicolumn{5}{|l|}{$\begin{array}{l}\text { Realiza tríplice } \\
\text { lavagem: }\end{array}$} \\
\hline $\operatorname{Sim}$ & 87 & 96 & 88 & 92,4 \\
\hline Não & 13 & 4 & 12 & 7,6 \\
\hline \multicolumn{5}{|l|}{$\begin{array}{l}\text { Destino final das } \\
\text { embalagens vazias } \\
\text { de agrotóxicos: }\end{array}$} \\
\hline Deixa no campo & 5 & 4 & 21 & 11,4 \\
\hline Lava e devolve & 90 & 90 & 64 & 78,9 \\
\hline Reutiliza & - & - & - & - \\
\hline Queima & 5 & 6 & 15 & 9,7 \\
\hline \multicolumn{5}{|l|}{$\begin{array}{l}\text { Destino dos resíduos } \\
\text { dos pulverizadores: }\end{array}$} \\
\hline Aplica no pomar & 95 & 95 & 97 & 95,7 \\
\hline Joga na terra & 2 & 3 & 3 & 2,9 \\
\hline Outro & 3 & 2 & - & 1,4 \\
\hline
\end{tabular}

Fonte: dados da pesquisa

O não uso do equipamento de proteção por aplicadores de agroquímicos representa dados preocupantes, como em Conceição do Araguaia, PA, apenas 3\% utilizam EPI, e $97 \%$ dos mesmos não fazem o manejo dos agrotóxicos com a proteção adequada (NASCIMENTO; SANTOS, 2012).A tríplice lavagem das embalagens é feita pela maioria dos produtores, 92,4\%e 78,9\% lavam e devolvem as embalagens, existindo um percentual geral de quase $11,4 \%$ que deixam as embalagens no campo e de $9,7 \%$ que as queimam. A maioria dos produtores $(95,7 \%)$ aplica os resíduos de agrotóxicos dos pulverizadores nos próprios pomares (Tabela 6). Essa realidade se repete muitas vezes, sendo mais agravante em outros polos de produção do Brasil, como no município de Conceição do Araguaia, PA, onde apenas $21 \%$ dos agricultores dão destino correto às embalagens, sendo que $68 \%$ dos lavradores queimam as embalagens após sua utilização; $4 \%$ reutilizam; e $7 \%$ as enterram (NASCIMENTO; SANTOS, 2012). 


\section{CONSIDERAÇÕES FINAIS}

As faixas etárias predominantes são dos fruticultores de Livramento de Nossa Senhora, BA, é acima de 41 anos e os produtores de maracujá os mais jovens. Os fruticultores apresentam baixo grau de escolaridade, o que dificulta a compreensão do uso dos agrotóxicos de forma correta; a maioria proprietário da terra sem residir na mesma. A maioria das áreas cultivadas está na faixa de 1 a 5 ha. As pragas e doenças são aquelas comuns a outras regiões produtoras. Há predomínio do uso de controle químico nas três fruteiras estudadas, com destaque para a cultura do maracujá. A assistência técnica por meio de órgãos públicos é insuficiente, sendo realizada, principalmente, pelos profissionais das casas comerciais. O uso de EPI não é prática persistente dos fruticultores e a lavagem dos equipamentos é realizada, na totalidade, em tanque de uso doméstico. Ações de educação sanitária devem ser desenvolvidas na região, com especial atenção aos produtores de maracujá que, por serem mais jovens, podem se tornar multiplicadores dos conhecimentos mínimos necessários para o uso de agrotóxicos.

\section{AGRADECIMENTOS}

Ao PNPD/CAPES, pelo financiamento da pesquisa; à Universidade Estadual do Sudoeste da Bahia-UESB; e à Agência Estadual de Defesa Agropecuária da Bahia-ADAB, pelo apoio na realização do trabalho.

\section{REFERÊNCIAS}

BEDOR, C. N. G.; RAMOS, L. O.; REGO, M. A. V. ; PAVÃO, A. C.; AUGUSTO, L. G. S. Avaliação e Reflexos da Comercialização e Utilização de Agrotóxicos na Região do Submédio do Vale do São Francisco. Revista Baiana de Saúde Pública. v. 31, n. 1, p. 68-76, 2007.

BEDOR, C. N. G.; Estudo do potencial carcinogênico dos agrotóxicos empregados na fruticultura e sua implicação para a vigilância da saúde. 2008 , 115f. Dissertação (Doutorado em Saúde Pública). Fundação Oswaldo Cruz. Recife.

BEDOR, C. N. G.; RAMOS, L. O. PEREIRA, P. J.; RÊGO, M. A. V. PAVÃO, A. C.; AUGUSTO,L. G. S. Vulnerabilidades e Situações de Riscos Relacionados ao Uso de Agrotóxicos na Fruticultura Irrigada. Revista Brasileira Epidemiológica. v. 12, n. 1, p. 39-49, 2009.

BRANDÃO, M. H. S. T. Diagnóstico da utilização de agrotóxicos e equipamento de proteção individual no polo de fruticultura de Livramento de Nossa Senhora, BA. 2009, 38f. Curso de Especialização em Epidemiologia com ênfase em Defesa Sanitária Vegetal. União Metropolitana para o Desenvolvimento da Educação e Cultura (UNIME). Lauro de Freitas, BA.

FARIA, N. M. X.; FACCHINI, L. A.; FASSA, A. G. TOMASI, E. Trabalho rural e intoxicações por agrotóxicos. Cadernos de Saúde Pública, Rio de Janeiro, v.20, n.5, p.1298-1308, 2004.

FARIA, N. M. X.; FASSA, A. G.; FACHINNI, L. A.. Intoxicação por agrotóxicos no Brasil: os sistemas oficiais de informação e desafios para realização de estudos epidemiológicos. Ciência e Saúde Coletiva. v. 12, n. 1, p. 25-38, 2007. 
FREITAS, A. L. G. E.; VILASBOAS, F. S.; PIRES, M. M.; SÃO JOSÉ, A. R. Caracterização da Produção e do Mercado da Graviola (Annona muricata) no Estado da Bahia. Informações Econômicas, SP, v. 43, n. 3, p.23-34, 2013.

GOUVEIA, V. F.; ROSSI, A. P.; ROSSI, A. P.; ROCHA, V. F.; RIBEIRO, L. F. C. Perfil dos produtores de guaraná (Paullinia cupana) no município de Alta Floresta - MT. Revista Conexão, v.8, n.2, p.300-311, 2012.

KIST, B. B.; VENCANTO, A. Z.; SANTOS, C.; CARVALHO, C.; REETZ, E. R.; POLL, H.; BELING, R. R. Anuário da Fruticultura 2012. Editora Gazeta, Santa Cruz, 2012, $128 p$.

KREUTZ, I. J.; PINHEIRO, S. L. G.; CAZELLA, A. A. A construção de novas atribuições para a assistência técnica e extensão rural: $A$ mediação com reconhecimento da identidade. Extensão Rural, Santa Maria, Ano XII, n. 12, p. 4169, 2005.

LIMA, A. C. S.; SOUZA, C. Z. F.; OLIVEIRA, A. H. C.; ALVES, J. M. A.; CORREIA, R. G. Diagnóstico fitossanitário e de práticas associadas ao uso de agrotóxicos nas hortas em ambiente protegido em Boa Vista - Roraima. Revista Agro@mbiente On-line, v. 5, n. 2, p. 124-133, 2011.

MATIAS, G. D. M.; SILVA, L. M. R.; KHAN, A. S. Perfil dos produtores de frutas do município de Limoeiro do Norte - CE frente ao novo paradigma de desenvolvimento do setor. Revista Ciência Agronômica, v.34, n. 1, p. 5-11, 2003.

MONQUERO, P. A.; INÁCIO, E. M.; SILVA, A. C. Levantamento de agrotóxico e utilização de equipamento de proteção individual entre os agricultores da região de Araras. Arquivos do Instituto Biológico, v. 76, n. 1, p. 135-139, 2009.

NASCIMENTO, T. P. A.; SANTOS, M. L. Diagnóstico do uso de agrotóxico em projetos de assentamento no município de Conceição do Araguaia - PA. In: III Congresso Brasileiro de Gestão Ambiental, 2012, Goiânia - GO. Anais eletrônicos. IBEAS, 2012. Disponível em: < http://www.ibeas.org.br/congresso/Trabalhos2012/XI001.pdf>. Acesso em: 14/06/2013.

OLIVEIRA, A.S. Perfil do produtor de pinha na Bahia, importância da broca-dosfrutos e eficiência de inseticidas no controle da praga. 2012, 99f. Dissertação (Ciências Agrárias - Defesa Agropecuária) Universidade Federal do Recôncavo da Bahia, Cruz das Almas.

PERES, F.; MOREIRA, J. C. Saúde e ambiente em sua relação com o consumo de agrotóxicos em um polo agrícola do Estado do Rio de Janeiro, Brasil. Caderno de Saúde Pública, Rio de Janeiro, v. 23, sup. 4, p. 5612-5621, 2007.

REICHERT, L. J.; PADILHA, M. C.; GOMES, M. C.; CÁCERES, R. S. Caracterização e análise da produção de batata nos municípios de São Lourenço do Sul - Brasil e Sanlúcar de Barrameda - Espanha. Extensão Rural, Santa Maria, Ano XVII, n.22, p.133-158, 2011. 
SECRETÁRIA DE AGRICULTURA, IRRIGAÇÃO E REFORMA AGRÁRIA (SEAGRI), Horticultura Baiana, $2010 . \quad$ Disponível em: <http://www.seagri.ba.gov.br/hortifruticultura_baiana.pdf>. Acesso em: 14 mai. 2013.

SILVA, M. V. A Utilização de Agrotóxicos em Lavouras Cafeeiras Frente ao Risco da Saúde do Trabalhador Rural no Município de Cacoal-RO (Brasil). 2006, 73f. Dissertação (Mestrado em Ciências da Saúde) Universidade de Brasília. Brasília.

SILVA, P. R.; FRANCISCO, V. L. F. S.; BAPTISTELLA, C. S. L. Caracterização da cultura do limão no estado de São Paulo, 2001-2007. Informações Econômicas, SP, v. 38, n. 7, p. 24-31, 2008.

SOUZA, A. A.; SANTOS NETO, F. G.; ARAÚJO, A. C. Diagnóstico da situação das hortas comunitárias da cidade de Parnaíba (PI). Diversa. Ano I, n. 1, p. 11-22, 2008.

ZARTH, N. A.; CITADIN, I.; PERONDI, M. A.; DONAZZOLO. Perfil sócio-econômico da vitivinicultura na região sudoeste do Paraná. Synergismus scyentifica UTFPR, v. 6 , n. 1, p. 20, 2011. 